\title{
A formação de professores para a educação inclusiva: legislação, diretrizes políticas e resultados de pesquisas
}

\section{The formation of teachers for the inclusive education: legislation, political guidelines and research results}

\author{
Márcia Denise Pletsch ${ }^{1}$
}

\begin{abstract}
RESUMO
Este artigo tem como objetivo levantar alguns aspectos relativos à formação de professores no Brasil, com ênfase para a inclusão de pessoas com necessidades educacionais especiais no ensino regular. Para tal tomaremos como base três referências: a legislação nacional e as diretrizes políticas específicas do Ministério da Educação (MEC); o resultado de pesquisas e a literatura especializada sobre o tema. O texto está organizado em três partes. Primeiro abordamos a fundamentação da formação de professores estabelecida nos documentos oficiais. Em seguida, apresentamos os resultados de diferentes pesquisas sobre o tema. Por fim, traçamos alternativas para a inclusão educacional.

Palavras-chave: educação inclusiva; formação de professores; resultados de pesquisas.
\end{abstract}

1. Educadora Especial com habilitação em Educação Especial pela Universidade Federal de Santa Maria (UFSM/Brasil), concluiu o Mestrado em Educação pela Universidade do Estado do Rio de Janeiro (UERJ/Brasil) em 2005, onde atualmente cursa o doutorado em Educação. Atua como professora de Pedagogia do Instituto Multidisciplinar da Universidade Federal Rural do Rio de Janeiro. 


\begin{abstract}
This article aims to raise some aspects related to the formation of teachers in Brazil, with emphasis to the inclusion of people with special educational needs in the regular education. For such, we will base ourselves in three references: the national legislation and the specific political guidelines of the Education Cabinet (MEC); the result of researches and the specialized literature over the theme. The text is organized in three parts. First, we deal with the grounding of the formation of teachers established in the official documents. Then, we show the results of different researches about the theme. At last, we trace alternatives for the educational inclusion.

Keywords: inclusive education; formation of teachers; research results.
\end{abstract}

Nos últimos dez anos, ocorreram avanços importantes em relação à formação de professores no Brasil, não apenas em termos de legislação, mas também em relação à produção do conhecimento acadêmico voltado para o tema.

Em relação à legislação, destaca-se como marco jurídico-institucional fundamental a Lei de Diretrizes e Bases da Educação Brasileira (LDB 9394/96), aprovada em 20 de dezembro de 1996. O objetivo dessa foi iniciar um processo de mudanças em todos os níveis da educação, que foram reorganizados em educação básica - que abarca a educação infantil, o ensino fundamental, o ensino médio - e ensino superior. A LDB dedica um capítulo à formação de professores, assinalando os fundamentos metodológicos, os tipos e as modalidades de ensino, bem como as instituições responsáveis pelos cursos de formação inicial dos professores. Também, no artigo 13, a LDB estabelece as incumbências dos professores, independentemente da etapa escolar em que atuam.

No artigo 87 nas Disposições Transitórias (Título IX)², a LDB instituiu a "Década da Educação", durante a qual todos os professores da educação básica deveriam ser habilitados em nível superior ou formados por treinamento em serviço. Vale lembrar que as Disposições Transitórias não se sobrepõem às definições da LDB. Por isso, o artigo 62 revogou o disposto nas Disposições Transitórias. Assim, continua-se admitindo professores formados em cursos de nível médio, na modalidade normal, para a educação infantil e as quatro primeiras séries do ensino fundamental. Literalmente:

2. Artigo 87 § 4. - - Até o fim da "Década da Educação" somente serão admitidos professores habilitados em nível superior ou formados por treinamento em serviço. 
Art. 62. A formação de docentes para atuar na educação básica farse-á em nível superior, em curso de licenciatura, de graduação plena, em universidades e institutos superiores de educação, admitida, como formação mínima para o exercício do magistério na educação infantil e nas quatro primeiras séries do ensino fundamental, a oferecida em nível médio, na modalidade Normal.

Nesse artigo, a LDB reafirma o ensino superior como nível desejável, apesar de admitir a formação mínima em curso normal para a atuação na educação infantil e nos anos iniciais do ensino fundamental. Essa deliberação foi confirmada por meio do parecer $n .{ }^{\circ} 1$ do Conselho Nacional de Educação (CNE), aprovado em 19 de fevereiro de 2003, segundo o qual todo professor concursado que atue em turmas de educação infantil ou séries iniciais do ensino fundamental tem assegurado o seu cargo, mesmo que não frequente curso em nível superior.

Com isso, perdem os educandos, os educadores e toda a sociedade, pois a profissão docente precisa dar respostas adequadas e fazer as necessárias intervenções que envolvem situações diversas e singulares do desenvolvimento humano. Assim, podemos justificar a formação em nível superior como uma das medidas essenciais a serem tomadas para que ocorram mudanças educacionais efetivas. Contudo, deve-se levar em consideração a heterogeneidade socioeconômica do Brasil, em que acabar com o modelo atual de formação de professores sem planejamento adequado poderia provocar consequências "catastróficas" para o sistema educacional.

Por outro lado, investimento na formação docente em nível superior por si só não resolverá a complexidade dos problemas educacionais brasileiros historicamente reproduzidos, como, por exemplo, o analfabetismo. É preciso compreender que mudanças na educação para atender ao paradigma vigente de inclusão educacional dependem de diversos fatores, como, por exemplo, o contexto social, econômico e cultural em que se insere a escola, as concepções e representações sociais relativas à deficiência e, por fim, os recursos materiais e os financiamentos disponíveis à escola (MENDES, 2002). Ou seja, a formação deve atender às necessidades e aos desafios da atualidade. Para tanto, sugerimos que o professor seja formado de maneira, a saber, mobilizar seus conhecimentos, articulando-os com suas competências mediante ação e reflexão teórico-prática.

Neste aspecto merece destaque a Proposta de Diretrizes para a Formação de Professores da Educação Básica em Cursos de Nível Superior (MEC, 2000). No item referente à formação de professores, assinalam-se as competências que 
devem ser dominadas como parte de um processo permanente de desenvolvimento profissional. Destacam-se aquelas referentes à compreensão do papel social da escola, ao domínio dos conteúdos, à interdisciplinaridade, ao conhecimento dos processos de investigação, ao gerenciamento do próprio desenvolvimento profissional e ao comprometimento com os valores estéticos, políticos e éticos inspiradores da sociedade democrática.

O documento acima referido aponta para uma revisão urgente do processo de formação inicial de professores, de modo a superar problemas em nível institucional e no campo curricular. No que se refere ao âmbito institucional, o documento assinala, entre outros, dois problemas centrais: a) a segmentação da formação dos professores, da qual a descontinuidade na formação dos alunos da educação básica é uma expressão; b) o distanciamento entre os cursos de formação e o exercício da profissão de professores no ensino fundamental e médio. Ambos os aspectos reforçam o fato de que a formação vem se dando sem uma maior articulação entre teoria e prática (MEC, 2000, p. 21-24).

Já no campo curricular, os principais problemas identificados na formação inicial de professores são: a) a desconsideração do repertório de conhecimentos dos professores no planejamento e desenvolvimento de ações pedagógicas; b) o uso desarticulado e o tratamento inadequado dos conteúdos das várias áreas do conhecimento na prática pedagógica; c) a falta de oportunidades para o seu desenvolvimento cultural; d) o tratamento restritivo da sua atuação profissional, ligado tão-somente à preparação para a regência de classe, deixando de lado outras dimensões fundamentais, como a sua participação na formulação do projeto político-pedagógico da escola, o seu relacionamento com alunos e com a comunidade; e) a ausência de estímulo para se desenvolver uma postura investigativa, capaz de relacionar teoria e prática; f) a ausência de conteúdos relativos às novas tecnologias da informação e comunicação; g) a desconsideração das especificidades próprias dos níveis e/ou modalidades de ensino em que são atendidos os alunos da educação básica; h) a desconsideração das especificidades das áreas do conhecimento que compõem o quadro curricular na educação básica (MEC, 2000, p. 24-34).

Por fim, a Proposta de Diretrizes para a Formação de Professores da Educação Básica delineia as exigências que se colocam para o desempenho do papel docente frente às novas concepções de educação do mundo contemporâneo:

Orientar e mediar o ensino para a aprendizagem dos alunos; responsabilizarse pelo sucesso da aprendizagem dos alunos; assumir e saber lidar com a diversidade existente entre os alunos; incentivar atividades de enriquecimento curricular; elaborar e executar projetos para desenvolver 
conteúdos curriculares; utilizar novas metodologias, estratégias e material de apoio; desenvolver hábitos de colaboração e trabalho em equipe (MEC, 2000 , p. 5 , grifo nosso).

Diversos estudos mais recentes têm reafirmado a necessidade da melhoria da formação de professores como condição essencial e premente para a promoção eficaz da inclusão de alunos com necessidades especiais em rede regular de ensino (BUENO, 1999a; CARNEIRO, 1999; MAGALHÃES, 1999; GLAT, 2000; GLAT; NOGUEIRA, 2002 e 2003; FERREIRA; GLAT; FERREIRA; OLIVEIRA; SENNA, 2003; BRAUN; SODRÉ; PLETSCH, 2003; GLAT; PLETSCH, 2004; PLETSCH, 2005; GLAT; PLETSCH, OLIVEIRA; ANTUNES, 2006; PLETSCH; FONTES, 2006). Não é para menos. A realidade evidenciada por uma pesquisa recente em âmbito nacional mostrou que os professores, de maneira geral, não estão preparados para receber em sua sala de aula alunos especiais (GLAT; FERREIRA; OLIVEIRA; SENNA, 2003).

Diagnóstico semelhante também foi traçado por Castro (2002) numa pesquisa realizada na rede municipal de educação de Santa Maria/RS, que analisou representações e sentimentos de professores da rede regular de ensino diante da inclusão de alunos com necessidades especiais em "suas" salas de aula. Castro mostrou que os professores, de modo geral, não se sentem capacitados para receber um aluno com deficiência, apesar de acreditarem nos méritos da inclusão. É o que se pode depreender das seguintes falas, proferidas por diferentes professores:

Eles [alunos especiais incluídos] exigem uma atenção que não temos condição de dar.

[...] Não temos condição de oferecer o que eles realmente necessitam, pois não somos educadoras especiais, apesar de termos boa vontade.

[...] Não temos preparo suficiente para fazer um trabalho com muitos resultados positivos.

[...] Há muito despreparo nas classes regulares e nos cursos de formação do magistério.

[...] Eu acho ruim [a inclusão], pois os professores precisam de conhecimento para trabalhar com esses alunos.

3. A pesquisa foi financiada pelo Banco Mundial, envolveu professores e alunos de graduação e pós-graduação da Universidade do Estado do Rio de Janeiro (UERJ), da Pontifícia Universidade Católica do Rio de Janeiro (PUC/RJ) e da Universidade Metodista de Piracicaba São Paulo. Disponível em: <www.cnotinfor.pt/projectos/worldbank/inclusiva>. 
[...] Desde que não atrase muito o ritmo do grupo em geral pode acontecer.

[...] É um direito assegurado a todos. E é possível a inclusão se o sistema educacional estiver preparado a aceitar e tiver conhecimento específico para lidar com as diferenças (p. 41-43).

Outrossim, devemos destacar o estudo desenvolvido por Carneiro (1999), que investigou professores que atuavam em turmas de pré-escola à 4. ${ }^{\mathrm{a}}$ série do ensino fundamental da rede regular de ensino de Juiz de Fora/MG. Os resultados evidenciaram a necessidade de uma formação continuada em serviço desses professores para a efetivação com qualidade da educação inclusiva. Já a pesquisa de Magalhães (1999), realizada na rede municipal de educação do Rio de Janeiro, ouviu a opinião de professores e diretores sobre a inclusão educacional de alunos especiais em rede regular de ensino, segundo a qual a formação de professores foi destacada como um aspecto relevante para a implementação da proposta inclusiva. Esses resultados foram confirmados pela pesquisa de Tonini e Costas (2005) realizada em uma escola pública estadual de Santa Maria/RS.

Diante do exposto, avaliamos que o despreparo e a falta de conhecimentos estão diretamente relacionados com a formação ou capacitação recebida. Além disso, podemos afirmar que existe um grande descrédito sobre a capacidade do aluno especial se desenvolver e agir de forma autônoma (GOFFMAN, 1988; GLAT, 1998).

Neste sentido, advertimos que, num primeiro momento, são comuns sentimentos de incapacidade e até mesmo de medo frente ao ingresso de um aluno com algum tipo de deficiência ou distúrbio de comportamento em sala de aula regular, podendo afastar o professor daquilo que não conhece e lhe suscitar estranheza (CORREIA, 1999; NAUJORKS, 2002 e 2003; BEYER, 2003). Em outras palavras, muitas vezes a falta de preparo e informação impede o professor de desenvolver uma prática pedagógica sensível às necessidades do aluno especial incluído.

Portanto, o atual e grande desafio posto para os cursos de formação de professores é o de produzir conhecimentos que possam desencadear novas atitudes que permitam a compreensão de situações complexas de ensino, para que os professores possam desempenhar de maneira responsável e satisfatória seu papel de ensinar e aprender para a diversidade. Para tanto, faz-se necessário elaborar políticas públicas educacionais voltadas para práticas mais inclusivas, adequar a formação de professores às novas exigências educacionais e definir um perfil profissional do professor, ou seja, habilidades e competências necessárias aos professores de acordo com a realidade brasileira (NUNES SOBRINHO; NAUJORKS, 2001). Essas parecem ser, hoje, medidas urgentes a serem adotadas 
para que ocorra uma mudança no status quo da educação inclusiva.

No que se refere ao conjunto de habilidades e competências necessárias aos professores para a prática com alunos incluídos, o Council for Exceptional Children $^{4}$ (CEC) estabelece balizas em nível internacional para a preparação, certificação e a prática do profissional em educação (NUNES SOBRINHO; NAUJORKS, 2001). Algumas delas devem ser aqui destacadas: a) partir da ideia de que "todos os alunos podem aprender", valorizando as potencialidades de aprendizagem de cada um; b) reafirmar que a aprendizagem é um processo individual, ocorrendo de maneira ativa em cada pessoa, de tal maneira que é o aluno que controla o seu processo de aprendizagem, sempre partindo do que sabe e influenciado por sua história pessoal e social; c) desenvolver a autoestima como uma das condições de aprendizagem, uma vez que o sentimento de pertencer a um grupo social, sentindo-se útil e valorizado, possibilita o agir e o crescer com o outro; d) estimular a autonomia dos alunos mediante a construção de sua aprendizagem; e) avaliar permanentemente as aprendizagens; f) avaliar o progresso de cada aluno segundo seu ritmo, do ponto de vista da evolução de suas competências ao resolver problemas de toda ordem e na participação da vida social; g) desenvolver a cooperação entre os alunos e certas formas de ensino mútuo, pois toda pedagogia diferenciada exige cooperação ativa dos alunos e dos seus pais, diminuindo a discriminação entre eles; $h$ ) envolver os alunos em suas aprendizagens e em seu trabalho, despertando o desejo de aprender e propondo tarefas cognitivas de maneira lúdica e interessante, a partir das quais deveria ser desenvolvido no educando a capacidade de auto-avaliação; i) inserir-se no universo cultural dos alunos (VALLE; GUEDES, 2003, p. 52-53).

Resumindo, podemos dizer que o professor deve valorizar a diversidade como aspecto importante no processo de ensino-aprendizagem. Além disso, necessita ser capaz de construir estratégias de ensino, bem como adaptar atividades e conteúdos, não só em relação aos alunos considerados especiais, mas para a prática educativa como um todo, diminuindo, assim, a segregação, a evasão e o fracasso escolar.

É relevante destacar que, de modo geral, a formação recebida pelos professores influencia diretamente no desenvolvimento dos alunos (LIBÂNEO, 1998). No caso específico aqui tratado, de fato, como ressalta Braibant, "a aquisição de competências e habilidades pelo aluno com necessidades especiais tem no professor o indispensável apoio e a orientação segura para o seu desenvolvimento" (1999 apud MEC/SEESP 2003, p. 37). Por outro lado, isto ocorre de forma mais intensa quando, a partir de sua formação, o professor alimenta sua

4. Conselho para Crianças Excepcionais (CEC) é uma organização internacional que tem como missão melhorar, com base em pesquisas empíricas, as práticas educacionais com indivíduos com necessidades especiais. Sua sede se localiza nos Estados Unidos. 
própria capacidade reflexiva no trabalho em equipe. Como salienta Ainscow (1997), a reflexão crítica em equipe é fundamental para criar as condições para a implementação da educação inclusiva.

Um fator que precisa ser levado em consideração quando se fala em formação de professores é a diversidade regional e socioeconômica do Brasil e seu rebatimento na universidade, instituição responsável pela formação de parte significativa dos professores. Esse aspecto é de grande importância e deve ser analisado no que tange aos investimentos necessários para o intercâmbio e a disseminação do conhecimento produzido pela academia (GATTI, 1996). Atualmente, são poucos os intercâmbios de experiências positivas de inclusão em âmbito nacional. Além disso, pouco se dissemina em termos de pesquisas empíricas envolvendo a temática. Com certeza esse aspecto fragiliza a implementação de políticas inclusivas (GLAT; SENNA; OLIVEIRA; FERREIRA, 2003; PLETSCH, 2005; PLETSCH; FONTES, 2006).

No Brasil, a formação de professores e demais agentes educacionais ligados à educação segue ainda um modelo tradicional, inadequado para suprir as reivindicações em favor da educação inclusiva. Vale destacar que, dentre os cursos de Pedagogia e de Pedagogia com habilitação em Educação Especial, poucos são aqueles que oferecem disciplinas ou conteúdos voltados para a educação de pessoas com necessidades especiais. Essa situação de carência no oferecimento de disciplinas e conteúdos vem ocorrendo apesar da exigência de um dispositivo legal pelo $\S 2 .^{\circ}$ do artigo 24 do Decreto n. $^{\circ} 3298$, de 20 de dezembro de 1999. Além desse Decreto, há também a Portaria n. ${ }^{\circ} 1793 / 94$, que recomenda a inclusão da disciplina "Aspectos ético-político-educacionais da normalização e integração da pessoa portadora de necessidades especiais" prioritariamente em todos os cursos de licenciatura.

O fato é que, de maneira geral, as licenciaturas não estão preparadas para desempenhar a função de formar professores que saibam lidar com a heterogeneidade posta pela inclusão. Isso é preocupante, pois os alunos bem ou mal estão sendo incluídos e cada vez mais as salas de aula se diversificam, embora, evidentemente, não no ritmo desejado (GLAT; PLETSCH, 2004; PLETSCH; FONTES, 2006). Em outras palavras, trata-se de uma inclusão precarizada.

Por outro lado, limitar-se a oferecer uma disciplina com conteúdos sobre crianças com necessidades especiais, sem maior reflexão e aprofundamento acerca das capacidades e individualidades humanas, pode acabar auxiliando a manutenção de práticas segregacionistas. É o que destaca Bueno: 
A inserção de uma disciplina ou a preocupação com conteúdos sobre crianças com necessidades educativas especiais pode redundar em práticas exatamente contrárias aos princípios e fundamentos da educação inclusiva: a distinção abstrata entre crianças que possuam condições para se inserir no ensino regular e as que não as possuam, e a manutenção de uma escola que, através de suas práticas, tem ratificado os processos de exclusão e de marginalização de amplas parcelas da população escolar brasileira (1999b, p. 18).

Frente a esse conjunto de problemas, vem ocorrendo todo um debate centrado na formulação de propostas para sua resolução. Uma parte da discussão tem se voltado para a questão da formação de professores. Trataremos aqui da proposta defendida por Bueno (1999a e 2001), segundo a qual o modelo inclusivo requereria a formação de dois tipos de professores: a) os chamados generalistas, que seriam responsáveis pelas classes regulares e capacitados com um mínimo de conhecimento e prática sobre a diversidade do alunado; b) os professores especialistas, capacitados em diferentes necessidades educacionais especiais e responsáveis para oferecer o necessário suporte, orientação e capacitação aos professores do ensino regular visando à inclusão, ou para atuar diretamente com alunos em classes especiais, salas de recurso ${ }^{5}$, etc. (BUENO, 1999a e 2001; GLAT, 2000; GLAT; NOGUEIRA, 2002 e 2003; GLAT; PLETSCH, 2004; MENDES, 2002 e 2004; PLETSCH, 2005).

É oportuno lembrar que a própria LDB (1996), em seu artigo 59, reconhece a importância de se formar professores especializados para atender pessoas com necessidades especiais, sob quaisquer modalidades de ensino:

Os sistemas de ensino assegurarão aos educandos com necessidades especiais:

III - professores com especialização adequada em nível médio ou superior, para atendimento especializado, bem como professores do ensino regular capacitados para a integração [leia-se, inclusão] desses educandos nas classes comuns (grifo nosso).

5. É uma modalidade de atendimento da Educação Especial que geralmente se dá num espaço destinado ao trabalho com os alunos portadores de necessidades especiais [lê-se alunos com necessidades educacionais especiais] incluídos em classes regulares, tendo como objetivo aprofundar conhecimentos que contribuam para o seu desenvolvimento e aprendizagem, com a utilização de recursos específicos que atendam às suas necessidades (IHA, 2001). 
De acordo com a proposta de Bueno acima referida, combinar-se-iam o trabalho do professor regular e a atuação do professor especializado, pois o generalista teria o mínimo de conhecimento e prática com alunos especiais, enquanto o especialista teria conhecimento aprofundado e prática sistemática no que concerne a necessidades educacionais específicas. A formação pedagógica do especialista deveria ser de caráter geral, com aprofundamentos específicos que permitiriam um atendimento especializado. Antes de tudo, portanto, seria um professor, encarregado de auxiliar o professor regular.

As linhas centrais dessa proposta constam do Plano Nacional de Educação (MEC, 2000), que aponta a integração entre professores da Educação Especial e da educação regular como uma das ações necessárias para efetivação da educação inclusiva. E acrescenta:

\begin{abstract}
Art. 8. As escolas da rede regular de ensino devem prever e prover na organização de suas classes:

I - professores das classes comuns e da educação especial capacitados e especializados, respectivamente, para o atendimento às necessidades educacionais especiais dos alunos;

II - condições para reflexão e elaboração teórica da educação inclusiva, com protagonismo dos professores, articulando experiência e conhecimento com as necessidades/possibilidades surgidas na relação pedagógica, inclusive por meio de colaboração com instituições de ensino superior e de pesquisa (grifo nosso).
\end{abstract}

Partindo desse pressuposto, propõe-se, como uma das alternativas para a efetivação da inclusão educacional na realidade brasileira o ensino itinerante (PLETSCH, 2005). Essa proposta pode ser entendida como um desdobramento da ideia de Bueno sobre os professores generalistas e especialistas, a qual, como se viu, tem fundamento na legislação e em diretrizes de política educacional do MEC.

O ensino itinerante, de acordo com o MEC (MEC/SEESP, 1995), consiste num suporte oferecido por um professor especializado ao professor regular que tem em sua classe alunos especiais. Além disso, o professor itinerante deve também dar apoio ao educando incluído, o qual pode ser individual ou em grupo, de acordo com as necessidades específicas de cada caso e, se necessário for, o professor itinerante pode ainda trabalhar com o aluno incluído em horário distinto do tempo de aula.

Em recente pesquisa etnográfica realizada na Rede Pública de Ensino da Cidade do Rio de Janeiro, foi evidenciado que o trabalho do professor 
itinerante constitui um instrumento favorável para a viabilização da inclusão de pessoas com necessidades especiais. $\mathrm{O}$ estudo mostrou que as professoras itinerantes podem atuar como agentes de mediação, sensibilização e mobilização pró-inclusão junto ao conjunto de personagens - diretores, coordenadores pedagógicos, professores regulares e demais funcionários - responsáveis pela dinâmica cotidiana das escolas. Seu trabalho, portanto, não se limita à questão pedagógica stricto sensu, mas envolve a esfera da cultura e dos valores constitutivos das relações intraescolares e da escola com a comunidade em seu entorno (PLETSCH, 2005).

No entanto, apesar das evidências claras a respeito da viabilidade e da potencialidade do ensino itinerante, não adianta apenas incluir os alunos especiais em classes regulares. É necessário mudar concepções preconceituosas a respeito do que seja educação inclusiva, bem como possibilitar aos professores regulares conhecimentos sobre essa proposta, já que a maioria não se sente preparada para receber esses alunos, como visto anteriormente.

Essa situação reforça a ideia de investimentos no ensino itinerante, não apenas como instrumento de suporte e capacitação aos professores regulares, mas também como agente de "internalização" nas escolas da política de inclusão de pessoas com necessidades especiais.

Por fim, para que ocorram mudanças efetivas no quadro educacional brasileiro em relação à inclusão de alunos com necessidades especiais, nunca é demais lembrar a necessidade de combater os problemas educacionais gerais, como, por exemplo, o fracasso e evasão escolares e a deterioração da qualidade do ensino público. Incluir pessoas com necessidades especiais no atual contexto de precarização, não rompe por si só com o circuito da exclusão. Por isso, a proposta de inclusão não pode ser pensada de maneira desarticulada da luta pela melhoria e transformação da educação brasileira como um todo.

\section{REFERÊNCIAS}

AINSCOW, M.; PORTER, G.; WANG, M. Caminhos para escolas inclusivas. Lisboa: Instituto de Inovação Cultural, 1997.

BRASIL. Lei de Diretrizes e Bases da Educação Nacional - LDB (Lei n. 9 9394/96). 20 de dezembro de 1996.

. Ministério da Educação. Portaria n. ${ }^{\circ}$ 1793/94. Brasília, 1994. 
. Conselho Nacional de Educação. Proposta de Diretrizes para a formação inicial de professores da educação básica, em cursos de nivel superior. Brasília, maio 2000 .

.Plano Nacional de Educação (Lei n. ${ }^{\circ}$ 10.172/01). 2000.

. Ministério da Educação. Decreto 3956/01. Brasília, out. 2001.

. Ministério da Educação. Secretaria de Educação Especial. Educação infantil - saberes e práticas para educação inclusiva. Brasília: MEC/SEESP, 2003.

BUENO, J. G. Crianças com necessidades educativas especiais, política educacional e a formação de professores: generalistas ou especialistas. Revista Brasileira de Educação Especial, v. 3, n. 5, p. 7-25, 1999a.

. Educação inclusiva: princípios e desafios. Revista Mediação, n. 1, p. 22-28, $1999 b$.

. A inclusão de alunos diferentes nas classes comuns do ensino regular. In: Temas sobre Desenvolvimento. São Paulo, v. 9, n. 54, p. 21-27, 2001.

BRAUN, P.; PLETSCH, M. D.; SODRÉ, J. A formação inicial e continuada de recursos humanos para a prática docente frente à educação inclusiva. In: NUNES SOBRINHO, F. de P. (Org.). Inclusão educacional - pesquisa e interfaces. Rio de Janeiro: Livre Expressão, 2003.

BEYER, H. O. A educação inclusiva: incompletudes escolares e perspectivas de ação. Cadernos de Educação Especial, Santa Maria, n. 22, 2003.

COUNCIL FOR EXCEPTIONAL CHILDREN. What every epecial education must knou: The international standards for the teacher. EUA, 2. ed., 1996.

CARNEIRO, R. C. A. Formação de professores na perspectiva da educação inclusiva. Dissertação (Mestrado - Programa de Pós Graduação em Educação) - Universidade do Estado do Rio de Janeiro, Rio de Janeiro, 1999.

CORREIA, L. de M. Alunos com necessidades educativas especiais nas classes regulares. Portugal: Editora Porto, 1999.

CASTRO, S. A representação social de professores de alunos incluídos em rede regular de ensino. Monografia (Conclusão de curso de especialização em Educação Especial na área da Deficiência Mental) - Universidade Federal de Santa Maria, Santa Maria/RS, 2002.

GLAT, R. Capacitação de professores: pré-requisito para uma escola aberta à diversidade. In: Revista Souza Marques, v. I, p. 16-23, 2000. 
. A integração social dos portadores de deficiência: uma reflexão. Sette Letras (Coleção Questões atuais em Educação Especial), Rio de Janeiro, v. I, 2.ed, 1998.

GLAT, R.; FERREIRA, J. R.; OLIVEIRA, E. da S. G.; SENNA, L. A. G. Panorama Nacional da Educação Inclusiva no Brasil. Relatório de consultoria técnica, Banco Mundial, 2003. Disponível. em: <www.cnotinfor.pt/projectos/worldbank/inclusiva $>$. Acesso em: nov./2003.

GLAT, R.; NOGUEIRA, M. L. de L. Políticas educacionais e a formação de professores para a educação inclusiva no Brasil. Revista Integração, Brasília, v. 24, ano 14, p. $22-27,2002$.

. A formação de professores para a Educação Inclusiva. Revista Comunicações, Piracicaba, 2003.

GLAT, R.; PLETSCH, M. D. O papel da Universidade frente às políticas públicas para educação inclusiva. Revista Benjamin Constant, Rio de Janeiro, p. 3-8, 2004.

GLAT, R.; ANTUNES, K. V. C.; OLIVEIRA, M.; PLETSCH, M. D. A educação especial no paradigma da inclusão: a experiência da rede pública municipal de educação do Rio de Janeiro. In: Encontro Nacional de Didática e Prática de Ensino, 13., 2006, Recife. Anais... Recife, 2006.

GATTI, B. A. Formação de professores no Brasil: problemas, propostas e perspectivas. Disponível em: <http://reduc.cl/reduc/gatti.pdf $>$. Acesso em: 23/5/2004.

GOFFMAN, E. Estigma - notas sobre a manipulação da identidade deteriorada. 4. ed. Rio de Janeiro: LTC, 1988.

MAGALHÃES, E. F. C. B. Viver a igualdade na diferença: a formação de educadores visando a inclusão de alunos com necessidades educacionais especiais no ensino regular. Dissertação (Mestrado) - Universidade do Estado do Rio de Janeiro (UERJ), Rio de Janeiro, 1999.

NAUJORKS, M. I.; NUNES SOBRINHO, F. de P. (Orgs.). Pesquisa em Educação Especial - O desafio da qualificação. Bauru: Edusc, 2001.

. Stress e inclusão: indicadores de stress em professores frente à inclusão de alunos com necessidades educacionais especiais. Revista Cadernos de Educação Especial, Santa Maria, n. 20, p. 117-125, 2002.

. Burnout docente no trabalho com a inclusão de alunos com necessidades educativas especiais. Revista Cadernos de Educação Especial, Santa Maria, n. 22, 2003. Disponível em: <www.ufsm.br/ce/revista>. 
PLETSCH, M. D. O professor itinerante como suporte para educação inclusiva em escolas da rede municipal de educação do Rio de Janeiro. Dissertação (Mestrado) Universidade do Estado do Rio de Janeiro (UERJ), Rio de Janeiro, 2005.

TONINE, A.; COSTAS, F. A. T. Escola inclusiva: o desvelar de um espaço multifacetado. Revista Educação Especial, Santa Maria, n. 26, 2005. Disponível em: <www.ufsm,br/ ce/revista $>$. Acesso em: 26/02/06.

VALE, M. H. F.; GUEDES, T. R. Habilidades e competências do professor frente à inclusão. In: NUNES SOBRINHO, F. de P. (Org.). Inclusão educacional - pesquisa e interfaces. Rio de Janeiro: Livre Expressão, 2003. 